\title{
Multi-axial fretting fatigue wear mechanisms of steel wires and the protection design
}

\author{
Dagang Wang*,a, Xiangru Wang, Chaoquan Tang, Xiaowu Li and Dekun Zhang
}

School of Mechatronic Engineering, China University of Mining and Technology, Xuzhou 221116, China

a'Email: wangdg@cumt.edu.cn, Tel:+8651683591916

*Dagang Wang

Keywords: steel wire, multi-axial fretting fatigue, dynamic wear evolution, fretting map, wear mechanism.

\begin{abstract}
Multi-axial fretting fatigue wear mechanisms of steel wires of hoisting rope and the protection design were explored in the present study. Multi-axial tension-torsion fretting fatigue behaviours of steel wires were investigated employing the self-made test rig. In order to quantitatively explore wear mechanisms of fatigue wires, and evolutions of wear scar size, wear depth and wear coefficient, surface morphologies of fatigue wires at distinct fatigue cycles were observed using the high speed digital microscopic system, three-dimensional white light interferometer and the scanning electron microscope. The results show that increases of fatigue cycles induce increases in the wear scar size and wear depth of fatigue wire, and an increase at first and then stabilization of wear coefficient. The contact status between contacting wires runs in the partial slip regime. The dissipated energy caused by tensile stress decreases with increasing fatigue cycles. The dissipated energy due to shear stress is relatively large during the whole test, which indicates the significant effect of shear stress on multi-axial fretting fatigue damage of fatigue wire. Wear mechanisms are mainly abrasive wear, adhesion wear, oxidation wear and fatigue wear.
\end{abstract}

\section{Introduction}

Total coal resources in China are approximately 5.57 trillion tons, and 53\% of the coal resources are buried below kilometers [1]. Hoisting rope is subjected to dynamic tension, bending and torsion loads during hoisting [2-4]. As the hoisting height reaches kilometer depth, the torsional stress greatly affects the service life of hoisting rope [2]. Service lives of hoisting ropes in some kilometer coal mines are no more than 6 months (two years' service life required in Coal mine safety regulations in China), which greatly affects safe and efficient production of deep coal mines [5]. Those loads will cause the contact load and relative displacement between contacting wires in hoisting rope, i.e. fretting wear [6]. The combined role of fretting wear and cyclic tension or torsion loads results in fretting fatigue [3]. Coupled fretting fatigue and cyclic torsion load induce tensiontorsion multiaxial fretting-fatigue of steel wire, which accelerates hoisting rope failure [7]. The fracture of hoisting rope (key transmission component of hoisting system) causes severe security incidents [3]. Therefore, it is of great significance to investigate tension-torsion multiaxial frettingfatigue behaviors of steel wire in order to prolong hoisting rope service life and to assure hoisting safety and reliability in kilometer deep coal mines.

In recent years, many scholars have carried out researches on axial tension-tension fretting fatigue behaviors of steel wires in distinct solutions. Perier et al. [8, 9] explored fretting fatigue behaviors of bridge rope wires in $\mathrm{NaCl}$ and water solutions. Zhao et al. [10] analyzed damage mechanisms, fretting regimes and fatigue fracture modes of steel wires in alkaline solutions. Zhang et al. [11] investigated the effect of strain ratio on the fretting regime, fretting wear mechanism, dissipated energy and fatigue fracture mode during fretting-fatigue. Wang et al. $[12,13]$ studied the wear coefficient evolution and crack propagation laws of steel wire during fretting-fatigue at air and at corrosive mediums with distinct $\mathrm{PH}$ values. Cruzado et al. [14] explored the effect of fretting damage on the decrease in fatigue life of steel wire. However, researches on tension-torsion multiaxial fretting fatigue wear mechanism of steel wire and the protection design have not been 
reported yet. Therefore, the objective study is to discuss the multiaxial fretting fatigue wear mechanism of steel wire during multiaxial fretting fatigue and its protection design.

\section{Experimental}

In order to evaluate multiaxial fretting fatigue behaviours of steel wire in hoisting rope, a selfmade multiaxial fretting fatigue test rig of steel wire was employed. The test rig can dynamically record the fatigue load, torque, torsion angle, contact load and tangential force between contacting wires, and the relative displacement. The schematic diagram of the test rig can be found in Figure. 1.

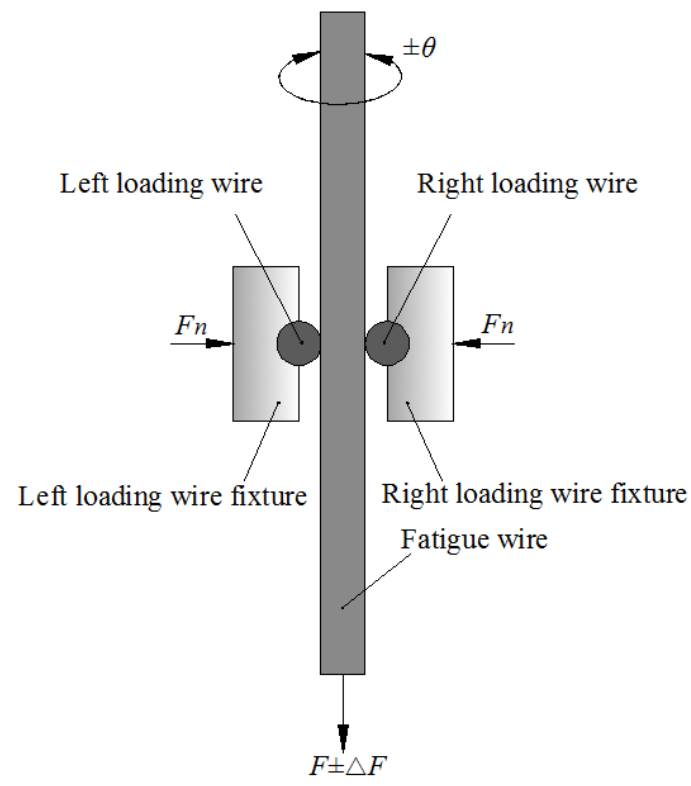

Figure. 1 Schematic diagram of the multiaxial fretting fatigue test rig of steel wire.

Steel wires in hoisting rope are chosen as the research object. Those wises are manufactured by the cold drawing process of high quality carbon structural steel. They are cylindrical with the diameter of $1 \mathrm{~mm}$ and length of $400 \mathrm{~mm}$. The chemical composition (in wt \%) of the wire material is shown in Table 1. The multiaxial fretting fatigue test parameters are shown in Table 2.

Table 1 Chemical composition of steel wire.

\begin{tabular}{ccccccc}
\hline Elements & $\mathrm{Zn}$ & $\mathrm{C}$ & $\mathrm{Mn}$ & $\mathrm{Si}$ & $\mathrm{Ni}$ & $\mathrm{Fe}$ \\
\hline $\begin{array}{c}\text { Mass } \\
\text { fraction(\%) }\end{array}$ & 4.53 & 0.84 & 0.39 & 0.02 & 0.01 & balance \\
\hline
\end{tabular}

Table 2 Multi-axial fretting fatigue test parameters .

\begin{tabular}{|c|c|c|c|c|c|c|c|}
\hline $\begin{array}{c}\text { Fretting } \\
\text { amplitude } \\
D(\mu \mathrm{m})\end{array}$ & $\begin{array}{l}\text { Stress } \\
\text { ratio }\end{array}$ & $\begin{array}{l}\text { Mean } \\
\text { stress } \\
(\mathrm{MPa}) \\
\end{array}$ & $\begin{array}{c}\text { Crossing } \\
\text { angle } \\
\left({ }^{\circ}\right)\end{array}$ & $\begin{array}{c}\text { Torsion } \\
\text { angle } \\
\left({ }^{\circ}\right)\end{array}$ & $\begin{array}{c}\text { Contact } \\
\text { load } \\
\text { Fn }(\mathrm{N})\end{array}$ & $\begin{array}{c}\text { Frequency } \\
\mathrm{f}(\mathrm{Hz})\end{array}$ & $\begin{array}{l}\text { Fatigue } \\
\text { cycles }\end{array}$ \\
\hline \pm 100 & 0.5 & 190.5 & 90 & \pm 4 & 25 & 5 & $\begin{array}{l}5000,10000 \\
15000,20000\end{array}$ \\
\hline
\end{tabular}

Evolutions of hysteresis loops of tangential force versus relative displacement and torque versus torsion angle were investigated to reveal contact states between contacting wires and the dissipated energy. Morphologies of wear scars of fatigue wires during multiaxial fretting-fatigue at distinct fatigue cycles were observed to explore multiaxial fretting fatigue wear mechanism employing the scanning electron microscope. 


\section{Results and discussion}

\subsection{Evolutions of fretting maps}

\subsubsection{Evolution of hysteresis loop of tangential force versus fretting amplitude}

It is clearly observed from Figure. 2 that hysteresis loops of tangential force versus fretting amplitude all exhibit non linear shapes, which is attributed to the tangential force lagging behind deformation due to internal friction of metal material [7]. During the initial stage, the hysteresis loop presents the parallelogram, which reveals the gross slip at the fretting contact zone. An increase of fatigue cycles induces the change of hysteresis loop from parallelogram to ellipse and thus the decreased slip amplitude and decreased sticking amplitude, which reveals the partial slip state $[15,16]$. The hysteresis loop maintains the stabilized ellipse with increasing fatigue cycles, which indicates the partial slip state.

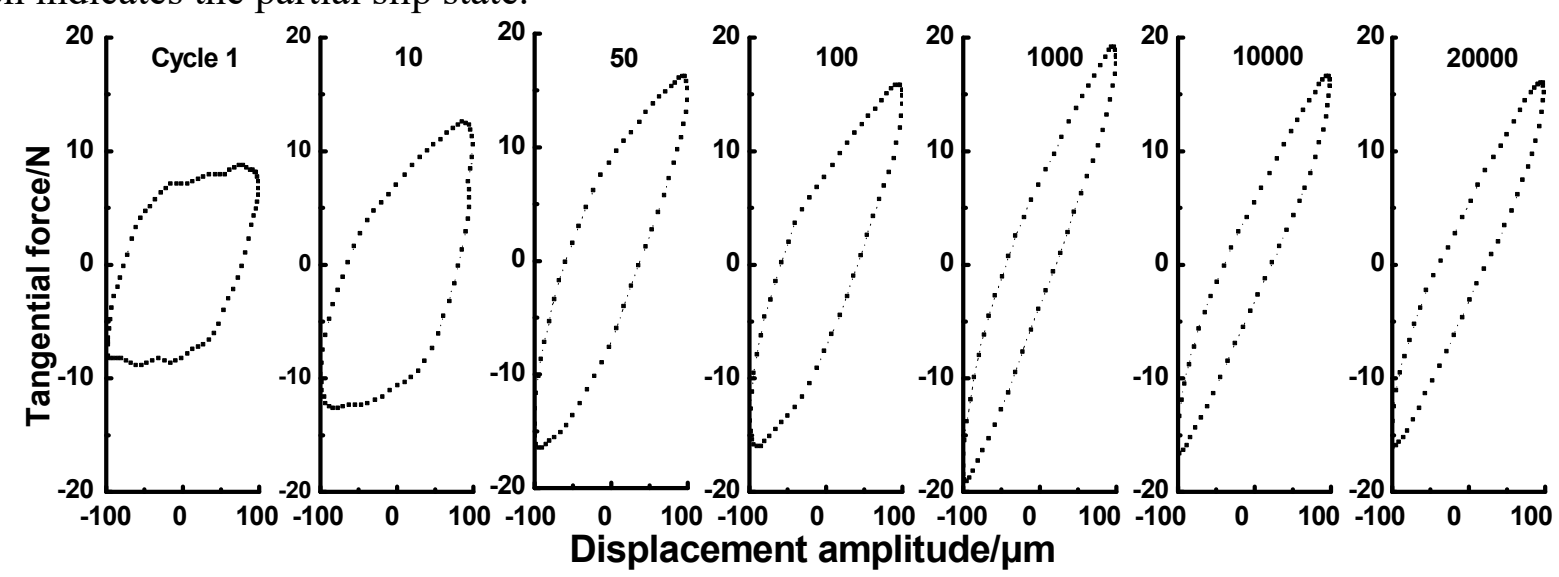

Figure.2 The evolution of tangential force-displacement amplitude hysteresis loop.

The area of hysteresis loop denotes the dissipated energy during multiaxial fretting-fatigue [17]. Large amounts of energy consumed during friction dissipate in the form of frictional heat induced by material removal. Therefore, larger dissipated energy causes larger multiaxial fretting fatigue damage. Figure. 3 shows larger dissipated energy during the initial stage and decreased dissipated energy with increasing fatigue cycles. That reveals larger multiaxial fretting fatigue damage during the initial stage as compared to decreased damage with increasing fatigue cycles.

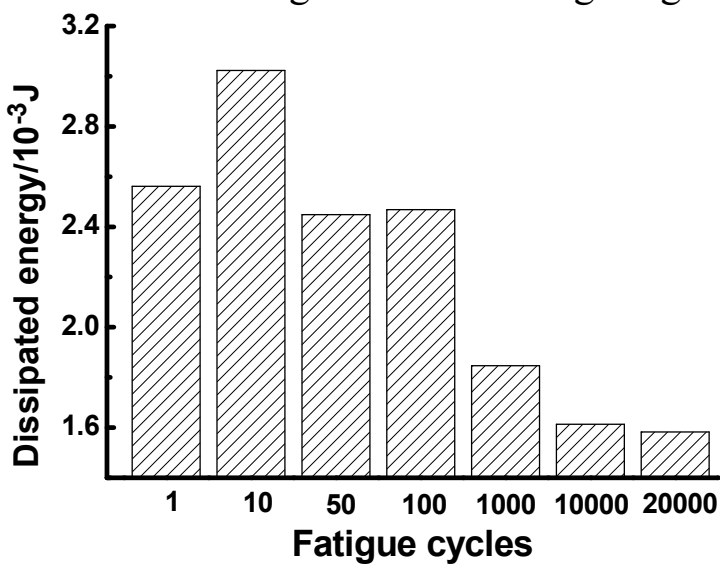

Figure.3 The evolution of dissipated energy with fatigue cycles.

\subsubsection{Evolution of hysteresis loop of torque versus torsion angle}

Figure. 4 shows large openness and areas of hysteresis loops of torque versus torsion angle during multi-axial fretting-fatigue, which reveals obvious lagging phenomenon of torsion angle behind torque and large dissipated energy consumed by shearing role attributed to torsion [7]. 
Those indicate the shear stress affects greatly the multiaxial fretting fatigue damage of fatigue wire.

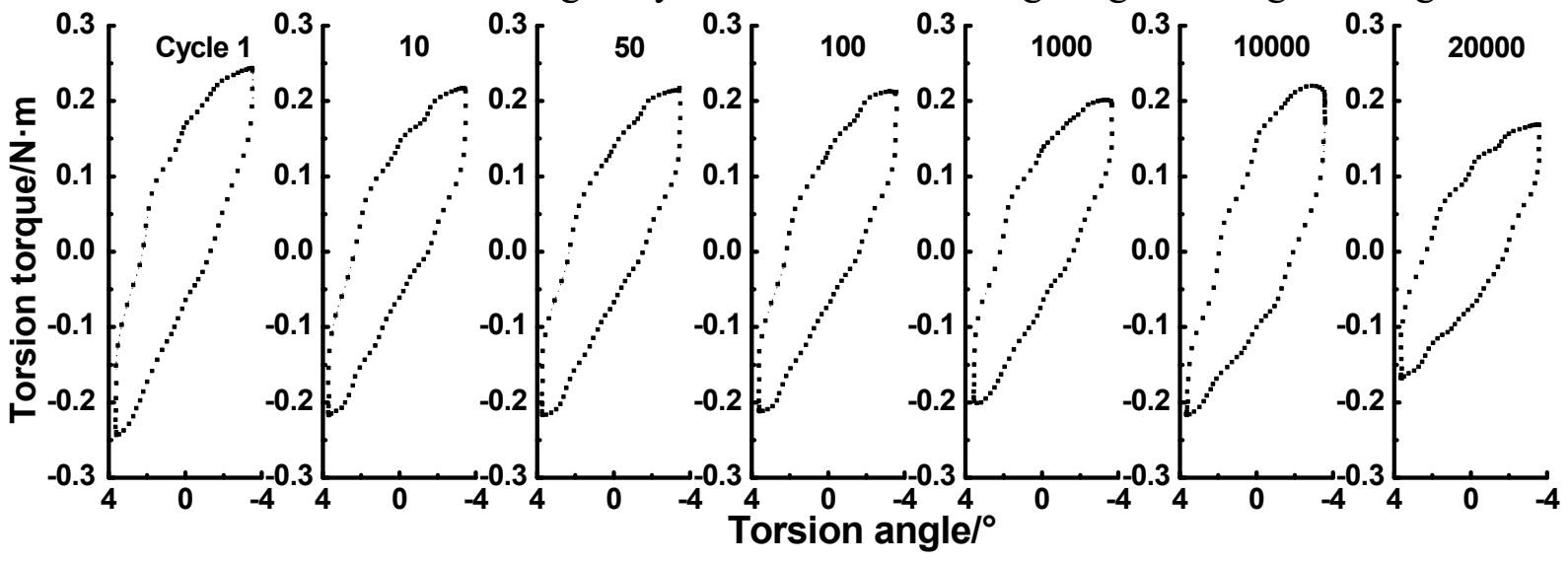

Figure.4 The evolution of hysteresis loop of torque vs. twist angle .

\subsection{Wear mechanisms}

Figure. 5a shows that wear scar presents hard particles, and wear debris at trailing edges during the initial stage. An increase of fatigue cycles induce ploughing phenomenon at the fretting contact surface attributed to movements of hard particles as shown in Figure. 5b. The combined role of tension and torsion loads induces the adhesion and plastic deformation attributed to continuous contact of large peaks, and surface material embrittlement due to severe work hardening. The coupled tensile and torsional stresses causes the crack initiation and propagation of surface material exhibits and the final peeling off as the debris as shown in Figure. 5c. Meanwhile, some debris are rapidly oxidized into hard particles as the third body adhered to the contact surface. Figure. 5d shows the crack initiated from the fretting contact surface propagated into the substrate with increasing fatigue cycles. Therefore, wear mechanisms of the fatigue wire are mainly abrasive wear, adhesive wear, oxidation wear and fatigue wear.

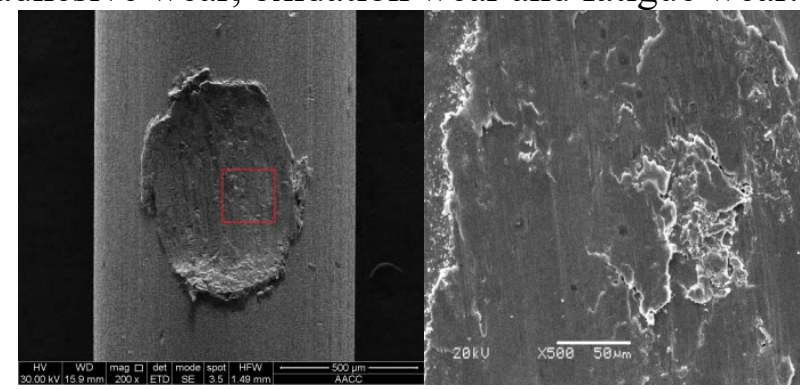

(a) 5000 cycles

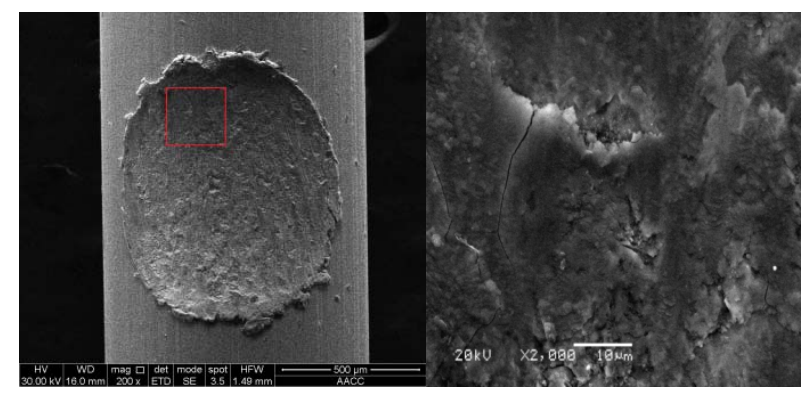

(c) 15000 cycles

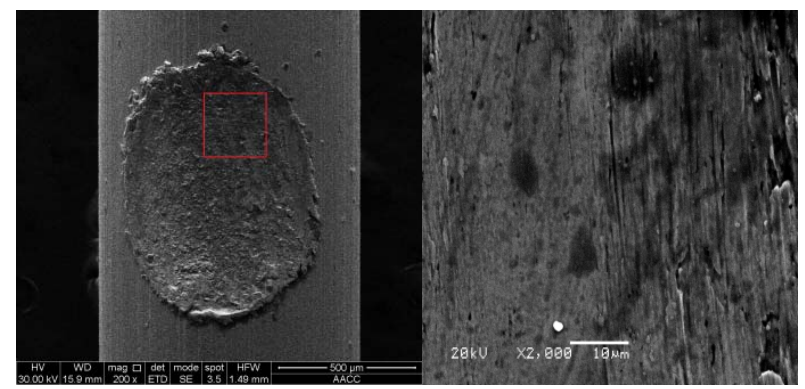

(b) 10000 cycles

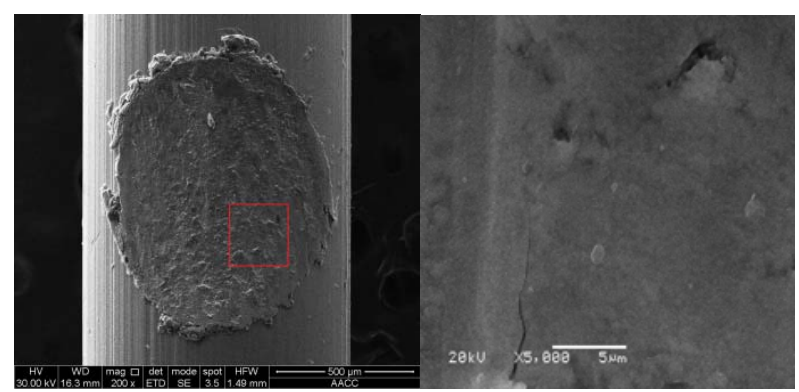

(d) 20000 cycles

Figure.5 Morphologies of wear scars by scanning electron microscopy at different fatigue cycles.

Figure. 6 shows that fatigue cracks initiate near trailing edges of wear scars, which is attributed to the partial slip state and stress concentration at the fretting contact surface [18]. At distinct fatigue cycles, the major axis of an ellipse exhibits a certain angle, $\theta 1$, with the fatigue wire axis 
attributed to the combined role of cyclic tension and torsion.
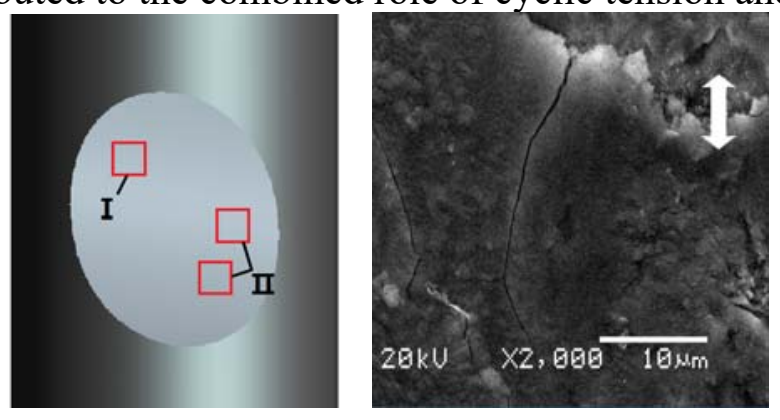

(a)Crack initiation locations

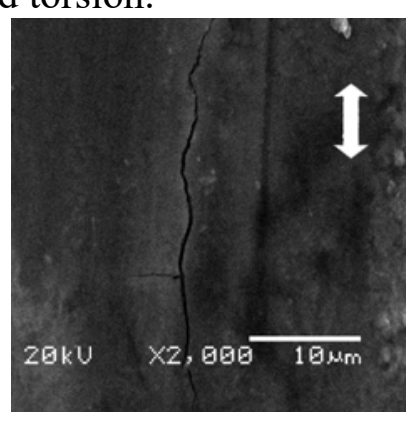

(I) 15000 cycles

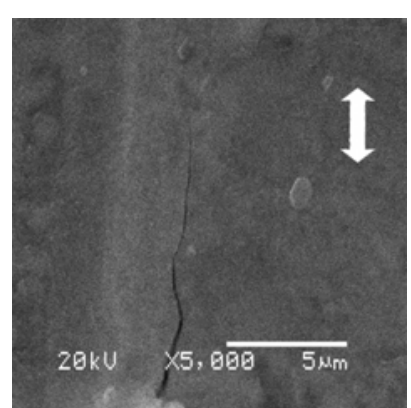

(II) 20000 cycles

Figure.6 Fretting fatigue crack initiation site and morphologies of crack at different fatigue cycles (arrows denoting the axial stress direction).

\subsection{Protection design of fretting damage}

Multiaxial fretting fatigue damage reduces the cross-section and tensile strength of steel wire, and thereby easily induces premature fatigue fracture of steel wire, which mainly accelerates the rope failure [19]. Therefore, protection design of fretting damage of the rope is of great importance to prolong the rope service life and hoisting safety in deep coal mines.

(1) Partial slip and mixed regimes easily cause the fatigue fracture of steel wire as compared to sticking and gross slip regimes. Fretting regimes are affected by multiaxial fretting fatigue parameters (fatigue stress, contact load, fretting amplitude and torsion amplitude) and lubricants [20]. Multiaxial fretting fatigue parameters depend on kinematic and kinetic parameters of hoisting system. Therefore, optimizations of coal mine hoisting parameters can reduce the wear and premature fracture of steel wires in the rope. Meanwhile, appropriate lubricants and grinding agents can be added to the rope to adjust the fretting regime during multiaxial fretting fatigue in order to reduce the damage degree [20].

(2) Line contact or surface contact wire ropes can be employed to increase the contact area and to decrease contact stress between contacting wires in order to avoid the stress concentration phenomenon. Special-shaped ropes, i.e. triangular, elliptical and flat wire ropes, can be employed to increase the contact area between the rope and friction lining, and thereby to decrease contact pressure between the rope and friction lining and between contacting wires in the rope [21]. Multiple stranded anti-torsion wire rope can be employed to avoid the damage attributed to torsional stress [21].

\section{Conclusions}

Evolutions of hysteresis loop of tangential force versus fretting amplitude reveal partial slip regime during multiaxial fretting-fatigue. Evolutions of hysteresis loop of torque versus torsion angle indicate large openness and areas of loops. The torsion effect greatly affects the damage of steel wire. The wear scar presents a great amount of ploughing and micro-cracks. The wear mechanisms are abrasive wear, oxidation wear, adhesion wear and fatigue wear.

\section{Acknowledgements}

The research reported here was supported by the National Natural Science Foundation of China (51405489; 61603394), Tribology Science Fund of State Key Laboratory of Tribology (SKLTKF13A04) and Natural Science Foundation of Jiangsu Province, China (BK20150185).

\section{References}

[1] Wang, D.G., Zhang, D.K. and Ge, S.R. (2014) Effect of terminal mass on fretting and fatigue parameters of a hoisting rope during a lifting cycle in coal mine. Engineering Failure Analysis, 
36(1), 407-422.

[2] Li, T., Miao, Y.j. and Hao, G.D. (2010) Preliminary exploration to reason for early breaking of wires in deep shaft. Coal Mine Machinery, 31(11), 94-96. (in Chinese)

[3] Wang, D.G. (2015) Study on mechanical modelling and fretting fatigue damage behaviors of hoisting rope. Changsha: Central South University Press.(in Chinese)

[4] Li, N. and Li, Y.J. (2015) Study and calculation on torsion of deep mine hoisting rope. Coal Engineering, 6, 21-23.(in Chinese)

[5] Wang, D.G., Zhang, D.K. and Ge, S.R. (2013) Finite element analysis of fretting fatigue behavior of steel wires and crack initiation characteristics. Engineering Failure Analysis, 28(3), 47-62.

[6] Zhang, D.K., Ge S.R and Zhu, Z.C. (2002) Friction and wear performance on fretting wear of steel wires. Journal of China University of Mining and Technology, 31(5), 367-370.(in Chinese)

[7] Liu, B., He G.Q, Jiang, X.S. and Zhu, M.H. (2012) Multi-axial fretting fatigue behavior [J]. Journal of Tongji University: Natural Science, 40(1), 77-80.(in Chinese)

[8] Périer, V., Dieng, L., Gaillet, L. Tessier, C. and Fouvry, S. (2009) Fretting-fatigue behavior of bridge engineering cables in a solution of sodium chloride. Wear, 267(1-4), 308-314.

[9] Périer, V., Dieng, L., Gaillet, L. and Fouvry, S. (2011) Influence of an aqueous environment on the fretting behavior of steel wires used in civil engineering cables. Wear , 271(9-10),15851593.

[10]Zhao, W.J., Zhang, D.K., Zhang, Z.F, Wang, S.Q. and Wang, S.B. (2012) Fretting fatigue behaviors of steel wires under neutral corrosive environment. Tribology, 32(3), 306-311.

[11] Zhang, D.K., Geng, H., Zhang, Z.F., Wang, D.G., Wang, S.Q. and Ge, S.R. (2013) Investigation on the fretting fatigue behaviors of steel wires under different strain ratios. Wear, 303,334-342.

[12]Wang, D.G., Li, X.W., Wang, X.R., Zhang, D.K. and Wang, D.A. (2016) Dynamic wear evolution and crack propagation behaviors of steel wires during fretting-fatigue. Tribology International, 101, 348-355.

[13]Wang, D.G., Zhang, D.K., Zhao, W.J. and Ge, S.R. (2014) Quantitative analyses of fretting fatigue damages of mine rope wires in different corrosive media. Materials Science \& Engineering A, 596(4), 80-88.

[14]Cruzado, A., Leen, S.B., Urchegui, M.A. and Gómez,X. (2013) Finite element simulation of fretting wear and fatigue in thin steel wires. International Journal of Fatigue, 55, 7-21.

[15]Zhou, Z.R. and Vincent, L. (1995) Mixed Fretting Regime. Wear, 181(95), 531-536.

[16]Zhou, Z.R. and Vincent, L. (1994) Effect of external loading on wear maps of aluminium alloys. Wear, 16(3), 233-233.

[17]Fouvry, S., Kapsa, P. and Vincent, L. (1996) Quantification of fretting damage. Wear, 200(1-2), 186-205.

[18]Zhou, W. (2007) Fretting fatigue crack initiation behavior and fatigue life prediction. Zhejiang University of Technology. (in Chinese)

[19]Zhang, D.K., Ge, S.R. and Xiong, D.S. (2001) Fretting wear behavior of hoisting rope in mining hoister. Tribology, 21(5), 362-365.(in Chinese)

[20]Shen, Y., Zhang, D.K., Duan, J.J. and Wang, D.G. (2011) Fretting wear behaviors of steel wires under friction-increasing grease conditions. Tribology International, 44(11), 1511-1517.

[21]Zhao, Z.H. and Li, Y.Q. (2005) Type selection and variety development trend of wier rope for mine. Steel Wire Products, 31(1), 1-3.(in Chinese) 